\title{
Continuous Flow Synthesis of $\alpha$-Trifluoromethylthiolated Esters and Amides from Carboxylic Acids: a Telescoped Approach
}

\author{
Francesca Franco, Sara Meninno, Alessandra Lattanzi,* Alessandra Puglisi, and Maurizio Benaglia* \\ Cite This: J. Org. Chem. 2021, 86, 14207-14212 \\ Read Online
}

ABSTRACT: A continuous flow approach to access $\alpha$-trifluoromethylthiolated esters and amides using commercially available arylacetic acids and $N$-(trifluoromethylthio)phthalimide as the electrophilic reagent is described. The experimental protocol involves the in-flow conversion of the carboxylic acid into $N$ acylpyrazole followed by the $\alpha$-trifluoromethylthiolation in a PTFE coil reactor and final reaction with primary or secondary amines, or alcohols, to afford in a telescoped process $\alpha$-substituted $\mathrm{SCF}_{3}$ amides and esters, respectively, in good overall yield and short reaction times.

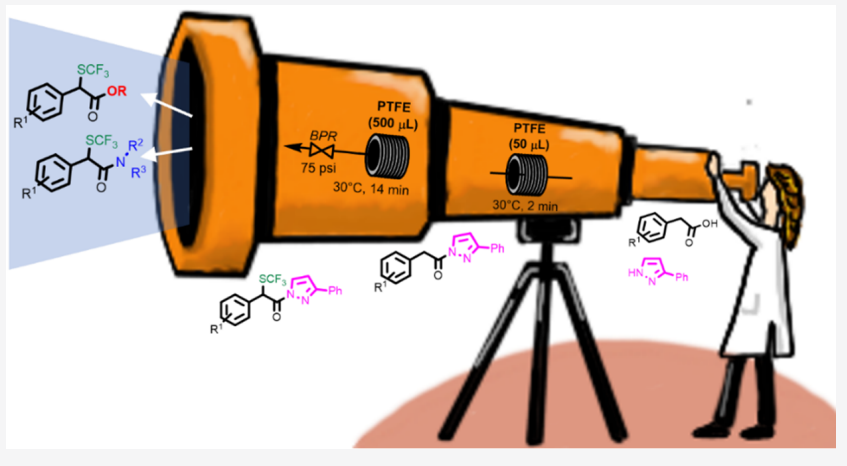

$\mathrm{T}$ he growing interest in academia and industrial context, toward effective and large-scale syntheses of intermediates and active pharmaceutical ingredients (APIs), has seen the flourishing of flow chemistry as a powerful enabling technology. ${ }^{1}$ An efficient optimization of the single transformations of a multistep synthesis, under better controlled and mild conditions, may lead to the development of telescoped processes, thus avoiding isolation of intermediates and maximizing efficiency, practicality, and environmental impact. $^{2}$

Fluorinated compounds find important applications in the pharmaceutical and agrochemical industries. ${ }^{3}$ Indeed, when the polar $\mathrm{C}-\mathrm{F}$ bond or fluorine-containing groups are present, the pharmacokinetics, lipophilicity, and bioavailability of the molecule is significantly affected and then can be modulated. ${ }^{4}$ Accordingly, over the past decades, many investigations have been undertaken to develop methods useful for installing fluorine-containing groups onto organic molecules. ${ }^{5}$

We recently reported the $\alpha$-trifluoromethylthiolation of $N$ acyl pyrazoles using $N, N, N^{\prime}, N^{\prime}$-tetramethyl-1,8-naphthalenediamine (proton sponge) as a catalytic base and $N$ (trifluoromethylthio)phthalimide as the electrophilic source. ${ }^{6}$ $\mathrm{N}$-Acylpyrazoles are readily available carboxylic acid surrogates, ${ }^{7}$ which were suitable for undergoing $\alpha$-functionalization via enolate formation under mild basic conditions (Scheme 1). In the same pot, the pyrazole group has been easily replaced by different nucleophiles, such as alcohols, amines, and water, to give the formal $\alpha$-trifluoromethylthiolation of carboxylic acid derivatives. Although this methodology enabled us to successfully obtain the $\alpha$-trifluoromethythiolated esters, amides, carboxylic acids, and other useful derivatives, the $N$ acyl pyrazoles had to be first synthesized from commercially
Scheme 1. Batch and Continuous-Flow Approaches to the Synthesis of $\alpha$-Trifluoromethylthio Carboxylic Acid Derivatives via $N$-Acylpyrazoles

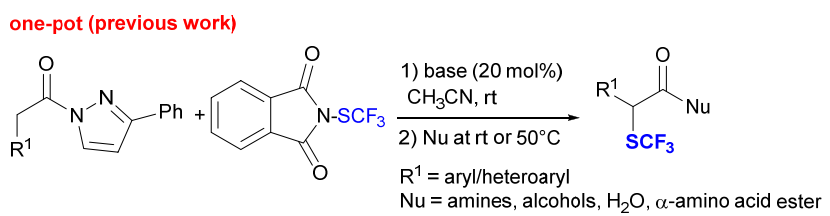

continuous telescoped flow approach (this work)

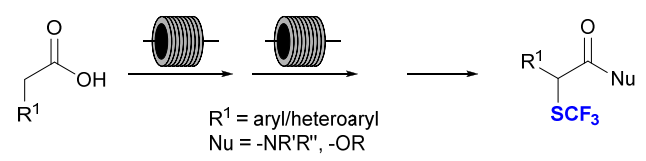

available aryl/heteroaryl acetic acids. To make the entire process more convenient and practical, we envisaged that a telescoped continuous flow protocol, ${ }^{8}$ starting directly from the commercially and readily available carboxylic acids, would have improved the method further (Scheme 1).

We started our investigation by studying the conversion of the carboxylic acid into the corresponding $\mathrm{N}$-acylpyrazole

Special Issue: Enabling Techniques for Organic Synthesis

Received: May 31, 2021

Published: July 27, 2021

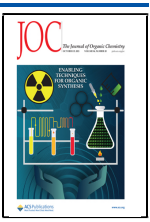


under continuous flow conditions using a PTFE coil reactor ( $1.58 \mathrm{~mm}$ outer diameter, $0.78 \mathrm{~mm}$ inner diameter) coiled in a bundle and immersed in an oil bath heated to the desired temperature. A $2.5 \mathrm{~mL}$ SGE gastight syringe A, containing phenylacetic acid and DMAP (0.1 mol/equiv) and a syringe B, containing 3 phenylpyrazole $(0.63 \mathrm{M}$ solution) and EDC* $\mathrm{HCl}$ $(1.2 \mathrm{~mol} / \mathrm{eq})$, were connected by a PEEK tee junction to a 500 $\mu \mathrm{L}$ PTFE coil reactor. In some explorative tests different solvents and flow rates were studied, and a few selected results are reported in Table 1 .

\section{Table 1. In Flow Synthesis of $N$-Acylpyrazoles ${ }^{a}$}

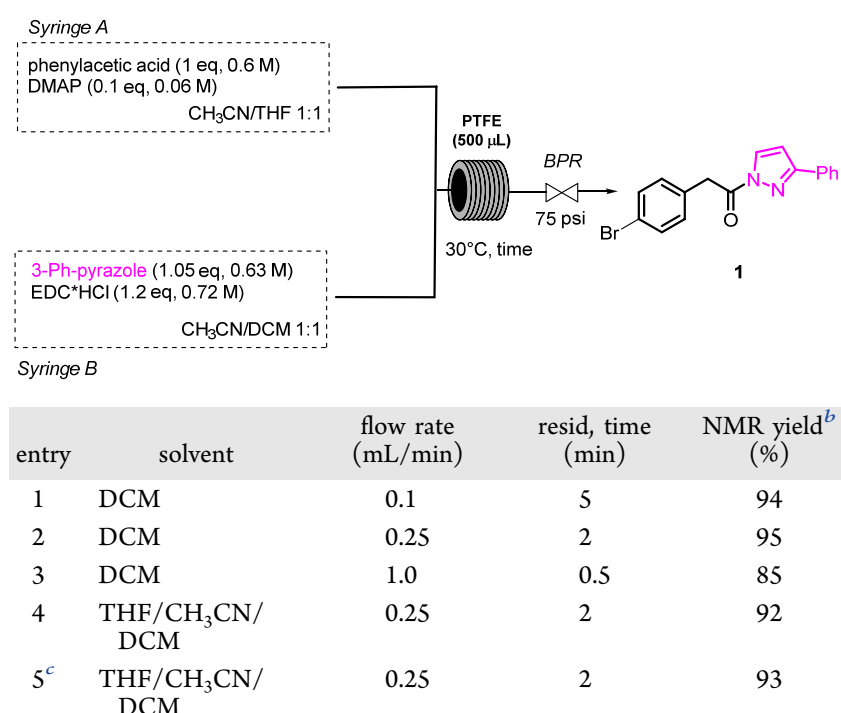

${ }^{a}$ Reaction conditions: concentration of $0.1 \mathrm{M}$ carboxylic acid. ${ }^{b}$ Yield determined by ${ }^{1} \mathrm{H}$ NMR analysis of crude reaction with 1,3,5trimethoxybenzene as an internal standard. ${ }^{c}$ Reaction run at a concentration of $0.3 \mathrm{M}$ carboxylic acid.

After only 2 min of residence time, product 1 was obtained in DCM in $95 \%$ yield. However, in view of the following steps in the continuous process, other solvent systems were investigated, and among them the THF/ $\mathrm{CH}_{3} \mathrm{CN} / \mathrm{DCM}$ mixture was found to be optimal also in the preparation of the $\mathrm{N}$-acylpyrazole ( $92 \%$ yield with $2 \mathrm{~min}$ residence time). Having established the conditions for a high yielding preparation of the activated ester, the trifluoromethylthiolation step was further investigated (Scheme 2).

Scheme 2. Synthesis of $\alpha$-Trifluoromethylthioamides from $\mathrm{N}$-Acylpyrazoles under Continuous Flow Conditions

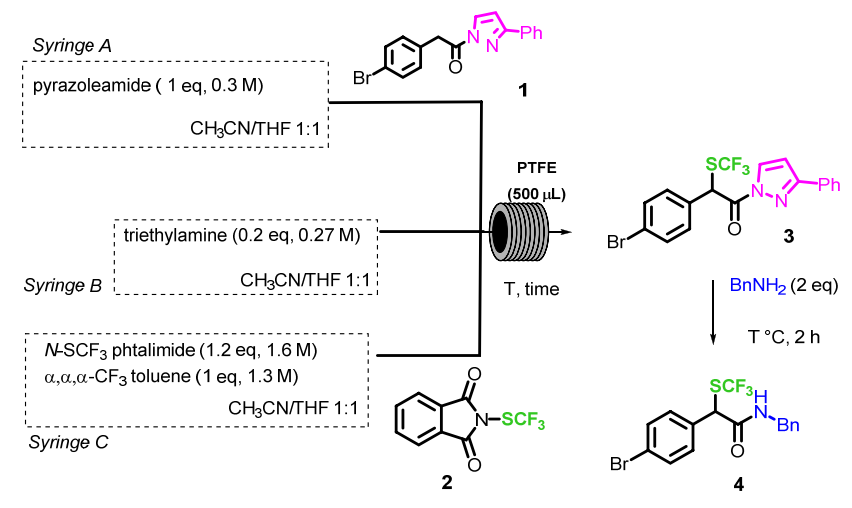

A $5 \mathrm{~mL}$ SGE gastight syringe, containing the pyrazoleamide of 4-bromophenylacetic acid $\mathbf{1}$ as a model substrate $(3 \mathrm{~mL}$ of a $0.3 \mathrm{M}$ solution in $\mathrm{CH}_{3} \mathrm{CN} / \mathrm{THF} 1: 1,1.0$ equiv) and two $1 \mathrm{~mL}$ SGE gastight syringes, containing a base $(0.27 \mathrm{M}$ solution in $\mathrm{CH}_{3} \mathrm{CN} / \mathrm{THF} 1: 1,0.2$ equiv) and $\mathrm{N}-\mathrm{SCF}_{3}$ phthalimide 2 (1.6 $\mathrm{M}$ solution in $\mathrm{CH}_{3} \mathrm{CN} / \mathrm{THF}$ 1:1, 1.2 equiv), respectively, were connected by a PEEK tee junction to a $500 \mu \mathrm{L}$ PTFE coil reactor. The outcome of the reactor, the pyrazole derivative 3 , was collected in a vial containing benzylamine ( 2 equiv), where it was stirred for further $2 \mathrm{~h}$ to afford $\mathrm{N}$-benzyl amide 4 . The yield was evaluated by ${ }^{19} \mathrm{~F}$ NMR and confirmed after chromatographic purification. At first, proton sponge (PS) was evaluated as a base, since it proved to be the base of election in the reaction. ${ }^{6}$ However, low yields were observed, due to solubility issues (Table 2 , entry $1-4$ ); therefore, other

Table 2. Synthesis of $N$-Benzyl $\alpha$-Trifluoromethylthioamide from $N$-Acylpyrazoles under Flow Conditions ${ }^{a}$

\begin{tabular}{llllcl} 
entry & \multicolumn{1}{c}{ solvent } & base & $\begin{array}{c}T \\
\left({ }^{\circ} \mathrm{C}\right)\end{array}$ & $\begin{array}{c}\text { resid time } \\
(\text { min })\end{array}$ & $\begin{array}{c}\text { yield }^{b} \\
(\%)\end{array}$ \\
1 & THF & PS & 25 & 30 & 0 \\
2 & THF & PS & 25 & 15 & 0 \\
3 & THF $/ \mathrm{CH}_{3} \mathrm{CN}(1: 1)$ & PS & 30 & 30 & 20 \\
4 & THF $/ \mathrm{CH}_{3} \mathrm{CN}(1: 1)$ & PS & 30 & 15 & 15 \\
5 & $\mathrm{THF} / \mathrm{CH}_{3} \mathrm{CN}(1: 1)$ & TEA & 30 & 30 & 61 \\
6 & $\mathrm{THF} / \mathrm{CH}_{3} \mathrm{CN}(1: 1)$ & TEA & 30 & 15 & 41 \\
7 & $\mathrm{THF} / \mathrm{CH}_{3} \mathrm{CN}(1: 1)$ & TEA & 45 & 15 & $52(51)$ \\
8 & $\mathrm{THF} / \mathrm{CH}_{3} \mathrm{CN}(1: 1)$ & TEA & 60 & 15 & $75(73)$ \\
9 & $\mathrm{THF} / \mathrm{CH}_{3} \mathrm{CN}(1: 1)$ & TEA & 90 & 15 & 50 \\
$10^{c}$ & $\mathrm{THF} / \mathrm{CH}_{3} \mathrm{CN}(1: 1)$ & TEA & 45 & 15 & 83 \\
$11^{d}$ & $\mathrm{THF} / \mathrm{CH}_{3} \mathrm{CN}(1: 1)$ & TEA & 45 & 15 & $85(83)$
\end{tabular}

${ }^{a}$ Reaction conditions: $0.2 \mathrm{~mol} /$ equiv of TEA was used. ${ }^{b}$ Yield determined by ${ }^{19} \mathrm{~F}$ NMR analysis of the crude reaction product with $\alpha, \alpha, \alpha-\mathrm{CF}_{3} \mathrm{C}_{6} \mathrm{H}_{5}$ as internal standard and in parentheses as yield after chromatographic purification. ${ }^{c} 0.35 \mathrm{~mol} /$ equiv of TEA. ${ }^{d} 0.5 \mathrm{~mol} /$ equiv of TEA.

conditions were investigated and the combination of triethylamine with acetonitrile/THF mixture was found to be a good solution and allowed to perform the reaction in continuo in $61 \%$ yield and $30 \mathrm{~min}$ residence time (entry 5). Higher productivity can be obtained by further increasing the flow rate (entry 6, productivity $=107.4 \mathrm{mg} / \mathrm{h}$ ), and better yields were achieved by operating at $60{ }^{\circ} \mathrm{C}(75 \%$ yield, entry 8 of Table 2$)$.

By further optimization work, where reaction temperature, base stoichiometry, and flow rates were studied, $45{ }^{\circ} \mathrm{C}$ was identified as the ideal reaction temperature, and 0.35 or 0.5 $\mathrm{mol} /$ equiv of TEA, and $15 \mathrm{~min}$ of residence time for a $0.5 \mathrm{~mL}$ PTFE coil reactor as good experimental set up (85\% yield, entries 10 and 11, Table 2 (see the Experimental Section for further details) affording a productivity $=217.4 \mathrm{mg} / \mathrm{h}$ of product 3. For the sake of comparison, the in-batch reaction, ${ }^{6}$ performed under the same experimental conditions (THF/ $\mathrm{CH}_{3} \mathrm{CN}$ (1:1), TEA), afforded $66 \mathrm{mg}$ of product 3 after $7 \mathrm{~h}$ reaction time, while the same amount was produced in flow after $20 \mathrm{~min}$. In order to proof the scalability of the method, the reaction was conducted using the same $0.5 \mathrm{~mL}$ PTFE reactor for $10 \mathrm{~h}$ under the optimized conditions of entry 10, Table 2, affording $2.02 \mathrm{~g}$ of $\mathrm{N}$-benzyl amide 4 .

The key step of the trifluoromethylthiolation was briefly investigated also with microreactor technology by using a 10 $\mu \mathrm{L}$ glass microreactor, observing a similar behavior and dependence of the yield from the temperature profile (Table 
3). Operating under the same experimental conditions, in $\mathrm{CH}_{3} \mathrm{CN}-\mathrm{THF}$ mixture and with TEA as a base, $65 \%$

Table 3. Synthesis of $\alpha$-Trifluoromethylthio Amide 4 from $\mathrm{N}$-Acylpyrazoles in Microreactors ${ }^{a}$

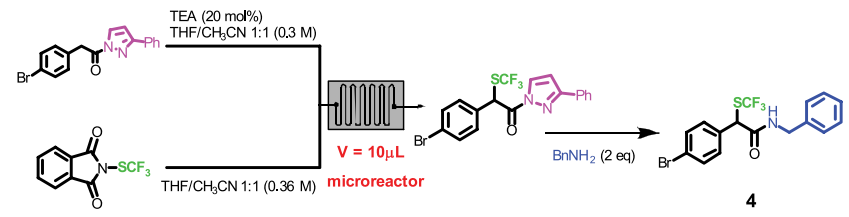

$\begin{array}{ccccc}\text { entry } & T\left({ }^{\circ} \mathrm{C}\right) & \text { flow rate }(\mu \mathrm{L} / \mathrm{min}) & \text { resid time }(\mathrm{min}) & \text { NMR yield }^{b}(\%) \\ 1 & 45 & 3 & 3.3 & 57 \\ 2 & 60 & 3 & 3.3 & 65 \\ 3 & 90 & 3 & 3.3 & 56 \\ 4 & 30 & 7.5 & 1.3 & 43 \\ 5 & 45 & 7.5 & 1.3 & 45 \\ 6 & 60 & 7.5 & 1.3 & 50 \\ 7 & 90 & 7.5 & 1.3 & 46\end{array}$

${ }^{a} 0.2$ molar equiv of TEA was used. ${ }^{b}$ Yield determined by ${ }^{19} \mathrm{~F}$ NMR analysis of the crude reaction with $\alpha, \alpha, \alpha-\mathrm{CF}_{3} \mathrm{C}_{6} \mathrm{H}_{5}$ as internal standard.

conversion for product 4 was obtained at $60{ }^{\circ} \mathrm{C}$ with 3.3 min of residence time and $50 \%$ conversion with $1.3 \mathrm{~min}$ residence time $(P=14.3 \mathrm{mg} / \mathrm{h}$ for entry $2, P=28 \mathrm{mg} / \mathrm{h}$ for entry 6).

Finally, the telescoped process was studied (Scheme 3).

The condensation of the arylacetic acid with pyrazole was performed in a $50 \mu \mathrm{L}$ PTFE coil reactor $(2$ min residence time), and then the outcome of the reactor was connected to another tee junction, fed by two $2.5 \mathrm{~mL}$ SGE gastight syringes, containing TEA and $\mathrm{N}-\mathrm{SCF}_{3}$ phthalimide, that were reacted at $30{ }^{\circ} \mathrm{C}$ in a second coil reactor $(0.5 \mathrm{~mL}, 14 \mathrm{~min}$ residence time). After the first volume was discarded, the outcome of the reactor was collected in a vial containing amine ( 2 equiv), where it was stirred for further $2 \mathrm{~h}$ (Table 4).

Some further optimization studies were necessary in order to set up an efficient multistep, telescopic process. Using a little excess of $\mathrm{N}-\mathrm{SCF}_{3}$ phthalimide (1.5 mol/equiv) and operating
Table 4. Telescoped Synthesis of $\alpha$-Trifluoromethylthio $N$ Benzylamide 4 from 4-Bromophenylacetic Acid

$\begin{array}{ccccc}\text { entry } & 2 \text { (molar equiv) } & \text { base (molar equiv) } & T\left({ }^{\circ} \mathrm{C}\right) & \text { yield }^{a}(\%) \\ 1 & 1.2 & 0.2 & 30 & 30 \\ 2 & 1.2 & 0.5 & 30 & 58(56) \\ 3 & 1.5 & 0.5 & 30 & 72(70) \\ 4 & 1.5 & 0.45 & 60 & 65 \\ 5 & 1.5 & 0.5 & 60 & 55 \\ 6 & 1.5 & 0.35 & 60 & 52 \\ 7^{b} & 1.5 & 0.5 & 60 & 50(48)\end{array}$

${ }^{a}$ Yield determined by ${ }^{19} \mathrm{~F}$ NMR analysis of crude reaction with $\alpha, \alpha, \alpha$ $\mathrm{CF}_{3} \mathrm{C}_{6} \mathrm{H}_{5}$ as internal standard and in parentheses as the yield after chromatographic purification. ${ }^{b}$ Residence time second reactor: $7 \mathrm{~min}$.

at $30{ }^{\circ} \mathrm{C}, 70 \%$ overall yield starting from the carboxylic acid was reached ( $P=183.4 \mathrm{mg} / \mathrm{h}$ of product 4 entry 3$)$.

Under the same experimental conditions, the multistep synthesis in flow of other amides was successfully achieved, in overall good yields (Figure 1).

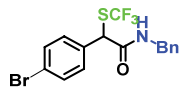

$470 \%$ yield

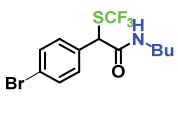

$560 \%$ yield

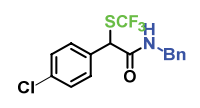

$655 \%$ yield

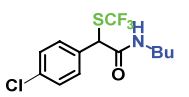

$750 \%$ yield

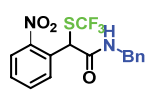

$851 \%$ yield

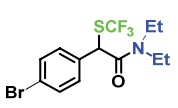

$930 \%$ yield $^{*}$

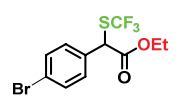

$1070 \%$ yield *
* Reaction of pyrazolamide with $\mathrm{E}_{2} \mathrm{NH}$ and $\mathrm{EtOH}$ was performed at $50^{\circ} \mathrm{C}$ for 8 hours

Figure 1. Telescoped synthesis of $\alpha$-trifluoromethylthioamides and esters from carboxylic acids.

Starting from the carboxylic acid, the protocol allowed to synthesize $\alpha$-trifluoromethylthio $N$-benzyl and $N$-alkyl amides in continuo in overall yields, ranging from 50 to $70 \%$. The $N, N$ dialkyl amide 9 was obtained in lower yield, likely ascribed to more sterically hindered nature of the amine, whereas the preparation of an ester derivative $\mathbf{1 0}$ was satisfactorily

\section{Scheme 3. Telescopic Synthesis of $\alpha$-Trifluoromethylthio Amides and Esters from Carboxylic Acids}

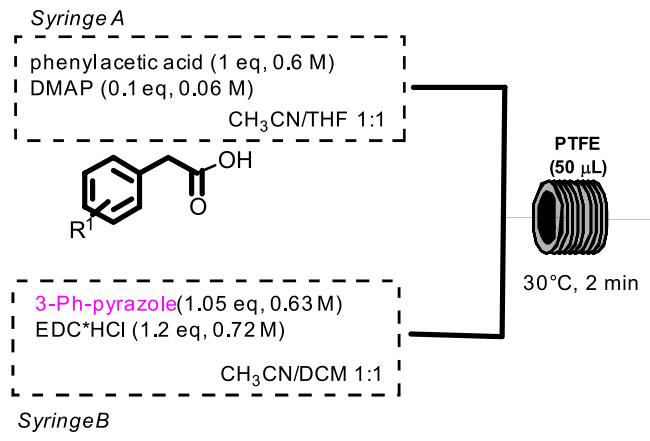

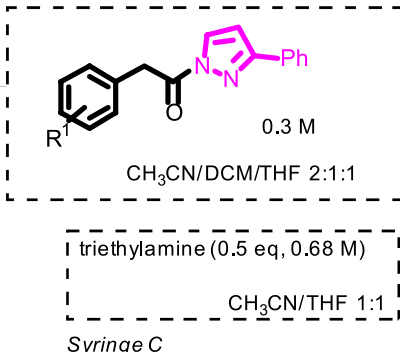

- - - - - - - - - - - - - -

$\mathrm{N}-\mathrm{SCF}_{3}$ phtalimide (1.5 eq, $\left.2.0 \mathrm{M}\right)$

$\alpha, \alpha, \alpha-\mathrm{CF}_{3}$ toluene $(1 \mathrm{eq}, 1.3 \mathrm{M})$

I $\mathrm{CH}_{3} \mathrm{CN} / \mathrm{THF} 1: 1$

Syringe $D$

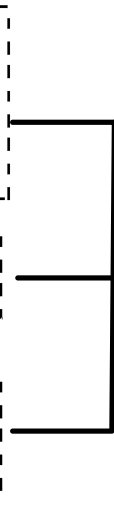


accomplished in $70 \%$ yield. In both cases, longer reaction times for the acyl substitution were necessary.

In conclusion, a telescopic process for the synthesis of $\alpha$ trifluoromethylthiolated esters and amides, using commercially available arylacetic acids and $N$-(trifluoromethylthio)phthalimide, was successfully accomplished. Micro- and mesoreactor technology was successfully employed to develop a multistep protocol for the in-flow synthesis of fluorinated derivatives in good yields and short reaction times, compared to the in-batch reactions. Based on the high versatility of the $\mathrm{N}$ acylpyrazoles as activated carboxylic acids, the methodology is expected to offer further opportunities for the development of many other telescopic processes to access a wide variety of useful derivatives.

\section{EXPERIMENTAL SECTION}

General Methods. All reactions requiring dry or inert conditions were conducted in flame-dried glassware under a positive pressure of nitrogen. Anhydrous THF, dicloromethane, and acetonitrile were purchased from Aldrich. Reactions were monitored by thin-layer chromatography (TLC) on Macherey-Nagel precoated silica gel plates $(0.25 \mathrm{~mm})$ and visualized by UV light. Flash chromatography was performed on Merck silica gel (60, particle size: $0.040-0.063$ $\mathrm{mm}) .{ }^{1} \mathrm{H},{ }^{13} \mathrm{C}$, and ${ }^{19} \mathrm{~F}$ NMR spectra were recorded on a Bruker Avance III HD 600, Bruker Avance-400, Bruker Avance-300, or Bruker Avance-250 spectrometer in $\mathrm{CDCl}_{3}$ as solvent at room temperature. Chemical shifts for protons are reported using residual solvent protons $\left({ }^{1} \mathrm{H}\right.$ NMR: $\delta=7.26 \mathrm{ppm}$ for $\left.\mathrm{CDCl}_{3}\right)$ as internal standard. Carbon spectra were referenced to the shift of the ${ }^{13} \mathrm{C}$ signal of $\mathrm{CDCl}_{3}(\delta=77.0 \mathrm{ppm})$. The following abbreviations are used to indicate the multiplicity in NMR spectra: s, singlet; $d$, doublet; $t$, triplet; q, quartet; dd, double doublet; ddd, doublet of doublet of doublets; dt, doublet of triplets; $\mathrm{m}$, multiplet; quint, quintuplet; sext, sextuplet sept, septet; br, broad signal; dq, doublet of quartets. Highresolution mass spectra (HRMS) were acquired using a Bruker solariX XR Fourier transform ion cyclotron resonance mass spectrometer (Bruker Daltonik GmbH, Bremen, Germany) equipped with a $7 \mathrm{~T}$ refrigerated actively shielded superconducting magnet. The samples were ionized in positive-ion mode using a MALDI or ESI ionization source. Melting points were measured with a Stuart Model SMP 30 melting point apparatus and are uncorrected. All starting materials (unless otherwise noted) were purchased from Aldrich and TCI used as received. $\mathrm{N}-\mathrm{SCF}_{3}$ phthalimide $\mathbf{2}$ and the pyrazolamides $\mathbf{1}$ were prepared by using general procedures reported in literature. ${ }^{10}$

Synthesis of $N$-Benzyl $\alpha$-Trifluoromethylthioamide (4) under Batch Conditions. In an oven-dried vial, under nitrogen atmosphere, TEA (5.6 $\mu \mathrm{L} 0.04 \mathrm{mmol}, 0.2$ equiv) was added to a mixture of $\mathrm{N}$-acylpyrazole $1(0.2 \mathrm{mmol}, 1$ equiv $)$ and $\mathrm{N}$ (trifluoromethylthio)phthalimide $2(59.3 \mathrm{mg}, 0.24 \mathrm{mmol}, 1.2$ equiv) in a mixture of anhydrous $\mathrm{CH}_{3} \mathrm{CN}$ and THF $(1: 1,1 \mathrm{~mL})$. The reaction mixture was stirred at room temperature and monitored by TLC. After completion of the first step, $N$-benzylamine $(0.26 \mathrm{mmol}$, 1.3 equiv) was added, and the mixture was stirred for $2 \mathrm{~h}$ at room temperature. After completion, the solvent was evaporated, and the crude mixture was purified by flash chromatography (eluent: hexane/ ethyl acetate $100 / 0$ to $80 / 20$ ) to afford products 4 in $70 \%$ yield.

General Flow Reactor Setup. The coil reactor was realized by using PTFE tubing $(1.58 \mathrm{~mm}$ outer diameter, $0.78 \mathrm{~mm}$ inner diameter) coiled in a bundle and immersed in an oil bath heated to the desired temperature. Reagent solutions were mixed using a PEEK T-mixer. The end of tubing chain connected to a 75 psi back-pressure regulator, and the outlet stream was collected in vial. For further details, see the Supporting Information.

In-Flow Synthesis of Acyl Pyrazole (1). Syringe A: $2.5 \mathrm{~mL}$ SGE gastight syringe containing 4-Br-phenylacetic acid $(2 \mathrm{~mL}$ of a $0.6 \mathrm{M}$ solution in $\mathrm{CH}_{3} \mathrm{CN} / \mathrm{THF}$ 1:1, $0.4 \mathrm{mmol}, 1.0$ equiv) and DMAP (0.06 M solution $\mathrm{CH}_{3} \mathrm{CN} / \mathrm{THF} 1: 1,0.04 \mathrm{mmol}, 0.1$ equiv) and Syringe B: $2.5 \mathrm{~mL}$ SGE gastight syringe containing 3 phenylpyrazole $(2 \mathrm{~mL}$ of a
$0.63 \mathrm{M}$ solution in $\mathrm{CH}_{3} \mathrm{CN} / \mathrm{DCM} 1: 1,0.42 \mathrm{mmol}, 1.05$ equiv) and EDC. $\mathrm{HCl}\left(0.72 \mathrm{M}\right.$ solution in $\mathrm{CH}_{3} \mathrm{CN} / \mathrm{DCM} 1: 1,0.48 \mathrm{mmol}, 1.2$ equiv), were connected by a PEEK tee junction to a $500 \mu \mathrm{L}$ PTFE coil reactor. Both syringes fed the solution at $125 \mu \mathrm{L} / \mathrm{min}$ giving a residence time of $2 \mathrm{~min}$. The system was pressurized at 75 PSI by applying a PEEK black pressure regulator. The outcome of the reactor was collected in a vial, and the solvent was evaporated. After the first five volumes were discarded, steady-state conditions were reached. The yield of product was evaluated by ${ }^{1} \mathrm{H}$ NMR, using 1,3,5trimethoxybenzene as an internal standard ( 0.33 equiv), and was reported as an average value calculated on three separately collected reactor volumes.

In-Flow Synthesis of $N$-Benzyl $\alpha$-Trifluoromethylthioamide (4). Syringe A: $5 \mathrm{~mL}$ SGE gastight syringe containing pyrazoleamide 1 ( $3 \mathrm{~mL}$ of a $0.3 \mathrm{M}$ solution in $\mathrm{CH}_{3} \mathrm{CN} / \mathrm{THF} 1: 1,0.9 \mathrm{mmol}$ ), Syringe $\mathrm{B}: 1 \mathrm{~mL}$ SGE gastight syringes containing TEA $(0.68 \mathrm{M}$ solution in $\mathrm{CH}_{3} \mathrm{CN} / \mathrm{THF} 1: 1,0.68 \mathrm{mmol}$ ), and Syringe C: $1 \mathrm{~mL}$ SGE gastight syringes containing $\mathrm{N}-\mathrm{SCF}_{3}$ phtalimide $\left(1.6 \mathrm{M}\right.$ solution in $\mathrm{CH}_{3} \mathrm{CN} /$ THF 1:1, $1.6 \mathrm{mmol})$ and $\alpha, \alpha, \alpha-\mathrm{CF}_{3}$ toluene as an internal standard (1.3 M solution in $\mathrm{CH}_{3} \mathrm{CN} / \mathrm{THF} 1: 1,1.3 \mathrm{mmol}$ ) were connected by a PEEK tee junction to a $500 \mu \mathrm{L}$ PTFE coil reactor. Syringe A fed the solution at $25 \mu \mathrm{L} / \mathrm{min}$, while both syringes $\mathrm{B}$ and $\mathrm{C}$ fed the solution at $5.5 \mu \mathrm{L} / \mathrm{min}$, giving a residence time of $14 \mathrm{~min}$ and a molar ratio in the reactor of pyrazoleamide ( $1 \mathrm{~mol} /$ equiv), TEA $(0.5 \mathrm{~mol} /$ equiv $), \mathrm{N}$ $\mathrm{SCF}_{3}$ phtalimide ( $1.2 \mathrm{~mol} /$ equiv), and $\alpha, \alpha, \alpha-\mathrm{CF}_{3}$ toluene ( 1 equiv). The outcome of the reactor was collected in a vial containing benzylamine ( $0.2 \mathrm{mmol}, 2$ equiv), where it was stirred for further $2 \mathrm{~h}$. The reaction mixture was dissolved in $\mathrm{CDCl}_{3}$ (without removing reaction solvent to avoid the evaporation of the internal standard) and subjected to ${ }^{19} \mathrm{~F}$ NMR, to evaluate the NMR yield of the product. ${ }^{11}$ After discarding the first reaction volume, steady-state conditions were reached. The yield was reported as an average value calculated on three separately collected reactor volumes. Reactor volumes were reunited and purified by column chromatography.

Telescoped Synthesis of $\alpha$-Trifluoromethylthioamides (49). Syringe A: $5 \mathrm{~mL}$ SGE gastight syringe containing the appropriate phenylacetic acid (0.6 M solution in $\mathrm{CH}_{3} \mathrm{CN} / \mathrm{THF} 1: 1,1.8 \mathrm{mmol}, 1$ equiv) and DMAP (0.06 M solution $\mathrm{CH}_{3} \mathrm{CN} / \mathrm{THF} 1: 1,0.18 \mathrm{mmol}$ 0.1 equiv) and Syringe B: $5 \mathrm{~mL}$ SGE gastight syringe, containing 3 phenylpyrazole $\left(0.63 \mathrm{M}\right.$ solution in $\mathrm{CH}_{3} \mathrm{CN} / \mathrm{DCM} 1: 1,1.89 \mathrm{mmol}$, 1.05 equiv) and $\mathrm{EDC} \cdot \mathrm{HCl}\left(0.72 \mathrm{M}\right.$ solution in $\mathrm{CH}_{3} \mathrm{CN} / \mathrm{DCM} 1: 1$, $2.16 \mathrm{mmol}, 1.2$ equiv) were connected by a PEEK tee junction to a 50 $\mu \mathrm{L}$ PTFE coil reactor. Both syringes fed the solution at $12.5 \mu \mathrm{L} / \mathrm{min}$ giving a residence time of $2 \mathrm{~min}$. The outcome of the reactor was connected by another tee junction to two $2.5 \mathrm{~mL}$ SGE gastight syringes: Syringe $\mathrm{C}$ containing TEA $\left(0.68 \mathrm{M}\right.$ solution in $\mathrm{CH}_{3} \mathrm{CN} /$ THF 1:1, $1.70 \mathrm{mmol}$ ) and Syringe D containing $\mathrm{N}-\mathrm{SCF}_{3}$ phtalimide 2 (2 $\mathrm{M}$ solution in $\mathrm{CH}_{3} \mathrm{CN} / \mathrm{THF} 1: 1,5.11 \mathrm{mmol}$ ) and $\alpha, \alpha, \alpha-\mathrm{CF}_{3}$ toluene as an internal standard $\left(1.3 \mathrm{M}\right.$ solution in $\mathrm{CH}_{3} \mathrm{CN} / \mathrm{THF} 1: 1$, $3.25 \mathrm{mmol}$ ). Both the syringes $\mathrm{C}$ and $\mathrm{D}$ fed the solution at $5.5 \mu \mathrm{L} /$ min, giving an overall residence time of $36 \mathrm{~min}$ and a molar ratio in the reactor of pyrazoleamide ( $1 \mathrm{~mol} /$ equiv), TEA $(0.5 \mathrm{~mol} /$ equiv $), N$ $\mathrm{SCF}_{3}$ phtalimide ( $1.5 \mathrm{~mol} /$ equiv), and $\alpha, \alpha, \alpha-\mathrm{CF}_{3}$ toluene (1 equiv). The system was pressurized at 75 PSI by applying a PEEK black pressure regulator. To avoid the precipitation of the $\mathrm{N}-\mathrm{SCF}_{3}$ reagent, syringe $\mathrm{D}$ was kept at $35{ }^{\circ} \mathrm{C}$. After discarding the first volume, the outcome of the reactor was collected in a vial containing the proper amine ( $0.2 \mathrm{mmol}, 2$ equiv), and the mixture was stirred for further $2 \mathrm{~h}$ at the temperature reported in Figure 1. The reaction mixture was dissolved in $\mathrm{CDCl}_{3}$ (without removing the reaction solvent to avoid the evaporation of the internal standard) and subjected to ${ }^{19} \mathrm{~F} \mathrm{NMR}$, to evaluate the yield of the product. The ${ }^{19} \mathrm{~F}$ NMR experiments were recorded with $\mathrm{d} 1=5 \mathrm{~s}$ to obtain a quantitative analysis. The yield was evaluated by the integral ratio between the signal of $\mathrm{SCF}_{3}$ group of the product $(\sim-40 \mathrm{ppm})$ and the signal of the $\mathrm{CF}_{3}$ group of the internal standard $(-63 \mathrm{ppm})$. The NMR yield was reported as an average value calculated on three separately collected reactor volumes. Reactor volumes were reunited and purified by column chromatography. 
N-Benzyl-2-(4-bromophenyl)-2-((trifluoromethyl)thio)acetamide (4). The compound was purified by flash silica gel column chromatography (hexane/ethyl acetate $100 / 0$ to $80 / 20$ ). White solid, $85.7 \mathrm{mg}$, $70 \%$ yield. Mp: $130.5-131.4{ }^{\circ} \mathrm{C} .{ }^{1} \mathrm{H} \mathrm{NMR}\left(\mathrm{CDCl}_{3}\right.$, $300 \mathrm{MHz}): \delta 7.53(\mathrm{~d}, 2 \mathrm{H}, J=8.3 \mathrm{~Hz}), 7.35-7.28(\mathrm{~m}, 5 \mathrm{H}), 7.22(\mathrm{~d}$, $2 \mathrm{H}, J=7.5 \mathrm{~Hz}), 6.26(\mathrm{br}, 1 \mathrm{H}), 4.99(\mathrm{~s}, 1 \mathrm{H}), 4.52(\mathrm{dd}, 1 \mathrm{H}, J=14.7$ $\mathrm{Hz}, J=5.7 \mathrm{~Hz}), 443(\mathrm{dd}, 1 \mathrm{H}, J=14.7 \mathrm{~Hz}, J=5.7 \mathrm{~Hz}) .{ }^{13} \mathrm{C}\left\{{ }^{1} \mathrm{H}\right\} \mathrm{NMR}$ $\left(\mathrm{CDCl}_{3}, 75 \mathrm{MHz}\right): \delta 167.1,137.0,134.4,132.4,129.7,129.7\left(\mathrm{q},{ }^{1} \mathrm{JCF}\right.$ $=308.3 \mathrm{~Hz}), 128.8,127.9,127.7,123.3,53.0,44.4 .{ }^{19} \mathrm{~F} \mathrm{NMR}\left(\mathrm{CDCl}_{3}\right.$, $282 \mathrm{MHz}$ ): $\delta-40.6$. HRMS (ESI-FT ICR) $\mathrm{m} / z:[\mathrm{M}+\mathrm{Na}]^{+}$Calcd for $\mathrm{C}_{16} \mathrm{H}_{13} \mathrm{BrF}_{3} \mathrm{NOSNa}$ 425.9751; Found 425.9759.

N-Butyl-2-(4-bromophenyl)-2-((trifluoromethyl)thio)acetamide (5). The compound was purified by flash silica gel column chromatography (hexane/ethyl acetate $100 / 0$ to $80 / 20$ ). White solid, $66.2 \mathrm{mg}$, $60 \%$ yield. $\mathrm{Mp}$ : $85.6-87.0{ }^{\circ} \mathrm{C} .{ }^{1} \mathrm{H} \mathrm{NMR}\left(\mathrm{CDCl}_{3}, 300\right.$ $\mathrm{MHz}): \delta 7.52(\mathrm{~d}, 2 \mathrm{H}, J=8.3 \mathrm{~Hz}), 7.30(\mathrm{~d}, 2 \mathrm{H}, J=8.3 \mathrm{~Hz}), 6.08(\mathrm{br}$, $1 \mathrm{H}), 4.96(\mathrm{~s}, 1 \mathrm{H}), 3.29$ (ddd, $2 \mathrm{H}, J=J=J \approx 7.0 \mathrm{~Hz}$ ), 1.49 (quint, $2 \mathrm{H}, J=7.3 \mathrm{~Hz}), 1.31($ sext, $2 \mathrm{H}, J=7.4 \mathrm{~Hz}), 0.92(\mathrm{t}, 3 \mathrm{H}, J=7.3 \mathrm{~Hz})$. ${ }^{13} \mathrm{C}\left\{{ }^{1} \mathrm{H}\right\}$ NMR $\left(\mathrm{CDCl}_{3}, 62.5 \mathrm{MHz}\right): \delta 167.0,134.5,132.3,129.74(\mathrm{q}$, $\left.{ }^{1} \mathrm{JCF}=308.4 \mathrm{~Hz}\right), 129.7,123.1,52.9,40.0,31.2,19.9,13.6 .{ }^{19} \mathrm{~F}$ NMR $\left(\mathrm{CDCl}_{3}, 376 \mathrm{MHz}\right): \delta-40.6$. HRMS (MALDI-FT ICR) $\mathrm{m} / z$ : $[\mathrm{M}+$ $\mathrm{H}]^{+}$Calcd for $\mathrm{C}_{13} \mathrm{H}_{16} \mathrm{BrF}_{3} \mathrm{NOS}$ 370.0083; Found 370.0094.

N-Benzyl-2-(4-chlorophenyl)-2-((trifluoromethyl)thio)acetamide (6). The compound was purified by flash silica gel column chromatography (hexane/ethyl acetate $100 / 0$ to $80 / 20$ ). White solid, $57.8 \mathrm{mg}$, $55 \%$ yield. Mp: $127.8-129.1{ }^{\circ} \mathrm{C} .{ }^{1} \mathrm{H}$ NMR $\left(\mathrm{CDCl}_{3}\right.$, $400 \mathrm{MHz}): \delta 7.33-7.29(\mathrm{~m}, 5 \mathrm{H}), 7.31(\mathrm{~d}, 2 \mathrm{H}, J=7.2 \mathrm{~Hz}), 7.17(\mathrm{~d}$, $2 \mathrm{H}, J=7.2 \mathrm{~Hz}), 6.51(\mathrm{br}, 1 \mathrm{H}), 5.01(\mathrm{~s}, 1 \mathrm{H}), 4.45(\mathrm{dd}, 1 \mathrm{H}, J=14.8$ $\mathrm{Hz}, J=5.8 \mathrm{~Hz}), 4.37(\mathrm{dd}, 1 \mathrm{H}, J=14.8 \mathrm{~Hz}, J=5.8 \mathrm{~Hz}) .{ }^{13} \mathrm{C}\left\{{ }^{1} \mathrm{H}\right\}$ NMR $\left(\mathrm{CDCl}_{3}, 100 \mathrm{MHz}\right): \delta 167.1,137.0,135.1,133.8,129.7$ (q, $\left.{ }^{1} \mathrm{JCF}=308.3 \mathrm{~Hz}\right), 129.4(2 \mathrm{C}), 128.8,127.9,127.7,52.9,44.3 .{ }^{19} \mathrm{~F}$ $\operatorname{NMR}\left(\mathrm{CDCl}_{3}, 376 \mathrm{MHz}\right): \delta-40.6$. HRMS (MALDI-FT ICR) $\mathrm{m} / z$ : $[\mathrm{M}+\mathrm{H}]^{+}$Calcd for $\mathrm{C}_{16} \mathrm{H}_{14} \mathrm{ClF}_{3} \mathrm{NOS} 360.0437$; Found 360.0431 .

N-Butyl-2-(4-chlorophenyl)-2-((trifluoromethyl)thio)acetamide (7). The compound was purified by flash silica gel column chromatography (hexane/ethyl acetate $100 / 0$ to $80 / 20$ ). White solid, $49.4 \mathrm{mg}$, 50\% yield. Mp: $72.7-73.7{ }^{\circ} \mathrm{C} .{ }^{1} \mathrm{H} \mathrm{NMR}\left(\mathrm{CDCl}_{3}, 300\right.$ $\mathrm{MHz}): \delta 7.36(\mathrm{~m}, 4 \mathrm{H}), 6.24(\mathrm{br}, 1 \mathrm{H}), 4.99(\mathrm{~s}, 1 \mathrm{H}), 3.28$ (ddd, $2 \mathrm{H}, J$ $=J=\mathrm{J} \approx 7.0 \mathrm{~Hz}), 1.48($ quint, $2 \mathrm{H}, J=7.4 \mathrm{~Hz}), 1.30($ sext, $2 \mathrm{H}, J=7.4$ $\mathrm{Hz}), 0.9(\mathrm{t}, 3 \mathrm{H}, J=7.3 \mathrm{~Hz}) \cdot{ }^{13} \mathrm{C}\left\{{ }^{1} \mathrm{H}\right\} \mathrm{NMR}\left(\mathrm{CDCl}_{3}, 75 \mathrm{MHz}\right): \delta$ 167.2, 135.0, 134.0, $129.80\left(\mathrm{q},{ }^{1} \mathrm{JCF}=308.2 \mathrm{~Hz}\right), 129.4,129.3,52.9$, 40.1, 31.2, 19.9, 13.6. ${ }^{19} \mathrm{~F}$ NMR $\left(\mathrm{CDCl}_{3}, 376 \mathrm{MHz}\right): \delta-40.7$. HRMS (ESI-FT ICR) $m / z:[\mathrm{M}+\mathrm{H}]^{+}$Calcd for $\mathrm{C}_{13} \mathrm{H}_{16} \mathrm{ClF}_{3} \mathrm{NOS} 326.0588$; Found 326.0574 .

N-Benzyl-2-(2-nitrophenyl)-2-((trifluoromethyl)thio)acetamide (8). The compound was purified by flash silica gel column chromatography (hexane/ethyl acetate $100 / 0$ to $80 / 20$ ). Colorless oil, $57.2 \mathrm{mg}, 51 \%$ yield. ${ }^{1} \mathrm{H}$ NMR $\left(\mathrm{CDCl}_{3}, 400 \mathrm{MHz}\right): \delta 8.07(\mathrm{~d}, 1 \mathrm{H}$, $J=1.4 \mathrm{~Hz}), 7.76-7.68(\mathrm{~m}, 2 \mathrm{H}), 7.55(\mathrm{t}, 1 \mathrm{H}, J=7.7 \mathrm{~Hz}), 7.35-7.22$ (m, 5H), $7.00(\mathrm{br}, 1 \mathrm{H}), 5.45(\mathrm{~s}, 1 \mathrm{H}), 4.54(\mathrm{dd}, 1 \mathrm{H}, J=14.9 \mathrm{~Hz}, J=$ $5.9 \mathrm{~Hz}), 4.41(\mathrm{dd}, 1 \mathrm{H}, J=14.9 \mathrm{~Hz}, J=5.7 \mathrm{~Hz}) .{ }^{13} \mathrm{C}\left\{{ }^{1} \mathrm{H}\right\} \mathrm{NMR}$ $\left(\mathrm{CDCl}_{3}, 150 \mathrm{MHz}\right): \delta 166.1,147.5,137.2,134.5,132.8,132.2,130.3$ $\left(\mathrm{q},{ }^{1} \mathrm{JCF}=308.4 \mathrm{~Hz}\right), 129.9,128.9,127.9,127.7,125.4,49.7,44.6 .{ }^{19} \mathrm{~F}$ NMR $\left(\mathrm{CDCl}_{3}, 376 \mathrm{MHz}\right): \delta-41.5$. HRMS (MALDI-FT ICR) $\mathrm{m} / z$ : $[\mathrm{M}+\mathrm{Na}]^{+}$Calcd for $\mathrm{C}_{16} \mathrm{H}_{13} \mathrm{~F}_{3} \mathrm{~N}_{2} \mathrm{O}_{3} \mathrm{SNa}$ 393.0497, Found 393.0472.

$\mathrm{N}, \mathrm{N}$-Diethyl-2-(4-bromophenyl)-2-((trifluoromethyl)thio)acetamide (9). The compound was purified by flash silica gel column chromatography (hexane/ethyl acetate $100 / 0$ to $80 / 20$ ). Pale yellow oil, $33.6 \mathrm{mg}$, $30 \%$ yield. ${ }^{\circ} \mathrm{C} .{ }^{1} \mathrm{H}$ NMR $\left(\mathrm{CDCl}_{3}, 400 \mathrm{MHz}\right): \delta 7.50(\mathrm{~d}$, $2 \mathrm{H}, J=8.4 \mathrm{~Hz}), 7.34(\mathrm{~d}, 2 \mathrm{H}, J=8.4 \mathrm{~Hz}), 5.28(\mathrm{~s}, 1 \mathrm{H}), 3.41(\mathrm{~m}, 1 \mathrm{H})$, $3.31(\mathrm{~m}, 2 \mathrm{H}), 3.21(\mathrm{~m}, 1 \mathrm{H}), 1.08(\mathrm{t}, 3 \mathrm{H}, J=7.2 \mathrm{~Hz}), 1.02(\mathrm{t}, 3 \mathrm{H}, J=$ $7.0 \mathrm{~Hz}) .{ }^{13} \mathrm{C}\left\{{ }^{1} \mathrm{H}\right\}$ NMR $\left(\mathrm{CDCl}_{3}, 100 \mathrm{MHz}\right): \delta 166.5,135.7,132.3$, $130.6\left(\mathrm{q},{ }^{1} \mathrm{JCF}=308.1 \mathrm{~Hz}\right), 129.8,122.9,51.9,42.5,41.0,14.0,12.5$. ${ }^{19} \mathrm{~F}$ NMR ( $\left.\mathrm{CDCl}_{3}, 376 \mathrm{MHz}\right): \delta-40.4$. HRMS (ESI-FT ICR) $\mathrm{m} / \mathrm{z}$ : $[\mathrm{M}+\mathrm{H}]^{+}$Calcd for $\mathrm{C}_{13} \mathrm{H}_{15} \mathrm{BrF}_{3} \mathrm{NOS}$ 370.0083, Found 370.0087 .

Telescoped Synthesis of Ethyl 2-(4-Bromophenyl)-2((trifluoromethyl)thio)acetate (10). Syringe A: $5 \mathrm{~mL}$ SGE gastight syringe containing 4-Br-phenylacetic acid ( $0.6 \mathrm{M}$ solution in $\mathrm{CH}_{3} \mathrm{CN} /$ THF 1:1, $1.8 \mathrm{mmol}, 1.0$ equiv) and DMAP (0.06 $\mathrm{M}$ solution $\mathrm{CH}_{3} \mathrm{CN} /$ THF 1:1, $0.18 \mathrm{mmol}, 0.1$ equiv) and Syringe B: $5 \mathrm{~mL}$ SGE gastight syringe containing 3-phenylpyrazole $(0.63 \mathrm{M}$ solution in $\mathrm{CH}_{3} \mathrm{CN} / \mathrm{DCM}$ 1:1, $1.89 \mathrm{mmol}, 1.05$ equiv) and $\mathrm{EDC} \cdot \mathrm{HCl}(0.72 \mathrm{M}$ solution in $\mathrm{CH}_{3} \mathrm{CN} / \mathrm{DCM}$ 1:1, $2.16 \mathrm{mmol}$, 1.2 equiv) were connected by a PEEK tee junction to a $50 \mu \mathrm{L}$ PTFE coil reactor. Both syringes fed the solution at $12.5 \mu \mathrm{L} / \mathrm{min}$ giving a residence time of $2 \mathrm{~min}$. The outcome of the reactor was connected by another tee junction to two $2.5 \mathrm{~mL}$ SGE gastight syringes: Syringe C containing TEA (0.68 M solution in $\mathrm{CH}_{3} \mathrm{CN} / \mathrm{THF} 1: 1,1.70 \mathrm{mmol}$ ) and Syringe D containing $\mathrm{N}$-SCF3 phtalimide (2) (2 M solution in $\mathrm{CH}_{3} \mathrm{CN} / \mathrm{THF} 1: 1,5.11$ mmol) and $\alpha, \alpha, \alpha-\mathrm{CF}_{3}$ toluene as an internal standard (1.3 $\mathrm{M}$ solution in $\mathrm{CH}_{3} \mathrm{CN} / \mathrm{THF} 1: 1,3.25 \mathrm{mmol}$ ). Both syringes $\mathrm{C}$ and $\mathrm{D}$ fed the solution at $5.5 \mu \mathrm{L} / \mathrm{min}$, giving an overall residence time of $36 \mathrm{~min}$ and a molar ratio in the reactor of pyrazoleamide $(1 \mathrm{~mol} / \mathrm{eq})$, TEA $(0.5$ $\mathrm{mol} /$ equiv), $\mathrm{N}-\mathrm{SCF}_{3}$ phtalimide (1.5 mol/equiv), and $\alpha, \alpha, \alpha-\mathrm{CF}_{3}$ toluene ( 1 equiv). The system was pressurized at 75 PSI by applying a PEEK black pressure regulator. To avoid the precipitation of the $\mathrm{N}$ $\mathrm{SCF}_{3}$ reagent, syringe $\mathrm{D}$ was kept at $35{ }^{\circ} \mathrm{C}$. The outcome of the reactor was collected in a vial containing ethanol ( $5 \mathrm{mmol}, 50$ equiv) and DMAP ( $1.3 \mathrm{mg}, 0.01 \mathrm{mmol}, 0.1$ equiv), and the mixture was stirred for a further $8 \mathrm{~h}$ at $50{ }^{\circ} \mathrm{C}$. The reaction mixture was dissolved in $\mathrm{CDCl}_{3}$ (without removing the reaction solvent to avoid the evaporation of the internal standard) and subjected to ${ }^{19} \mathrm{~F}$ NMR to evaluate the yield of the product. The ${ }^{19} \mathrm{~F}$ NMR experiments were recorded with $\mathrm{d} 1=5 \mathrm{~s}$ to obtain a quantitative analysis. The yield was evaluated by the integral ratio between the signal of $\mathrm{SCF}_{3}$ group of the product $(\sim-40 \mathrm{ppm})$ and the signal of the $\mathrm{CF}_{3}$ group of the internal standard $(-63 \mathrm{ppm})$. The NMR yield was reported as an average value calculated on three separately collected reactor volumes. Reactor volumes were reunited and purified by column chromatography (eluent: hexane/ethyl acetate $100 / 0$ to $90 / 10$ ). Pale yellow oil, $72.8 \mathrm{mg}, 70 \%$ yield. ${ }^{1} \mathrm{H}$ NMR $\left(\mathrm{CDCl}_{3}, 300 \mathrm{MHz}\right): 7.51(\mathrm{~d}, 2 \mathrm{H}, J=8.3$ $\mathrm{Hz}), 7.33(\mathrm{~d}, 2 \mathrm{H}, J=8.3 \mathrm{~Hz}), 5.00(\mathrm{~s}, 1 \mathrm{H}), 4.25(\mathrm{dq}, 1 \mathrm{H}, J=15.8 \mathrm{~Hz}$, $J=7.1 \mathrm{~Hz}), 4.19(\mathrm{dq}, 1 \mathrm{H}, J=15.8 \mathrm{~Hz}, J=7.1 \mathrm{~Hz}), 1.25(\mathrm{t}, 3 \mathrm{H}, J=7.1$ $\mathrm{Hz}) .{ }^{13} \mathrm{C}\left\{{ }^{1} \mathrm{H}\right\} \mathrm{NMR}\left(\mathrm{CDCl}_{3}, 75 \mathrm{MHz}\right): \delta 168.4,133.3,132.2,129.8$, $129.6\left(\mathrm{q},{ }^{1} \mathrm{JCF}=306.9 \mathrm{~Hz}\right), 123.3,62.8,50.9,13.8 .{ }^{19} \mathrm{~F}$ NMR $\left(\mathrm{CDCl}_{3}, 376 \mathrm{MHz}\right): \delta-41.0$. HRMS (ESI-FT ICR) $\mathrm{m} / z:[\mathrm{M}+\mathrm{Na}]^{+}$ Calcd for $\mathrm{C}_{11} \mathrm{H}_{10} \mathrm{BrF}_{3} \mathrm{O}_{2} \mathrm{SNa}$ 364.9408, Found 364.9429.

\section{ASSOCIATED CONTENT}

\section{Supporting Information}

The Supporting Information is available free of charge at https://pubs.acs.org/doi/10.1021/acs.joc.1c01270.

Flow setup for synthesis of $\alpha$-trifluoromethylthioamide 4 and telescoped synthesis of $\alpha$-trifluoromethylthio carboxylic acid derivatives. Copies of ${ }^{1} \mathrm{H}$ NMR and ${ }^{13} \mathrm{C}$ NMR spectra for all compounds (PDF)

\section{AUTHOR INFORMATION}

\section{Corresponding Authors}

Maurizio Benaglia - Dipartimento di Chimica, Università degli Studi di Milano, 20133 Milano, Italy; ㅇorcid.org/ 0000-0002-9568-9642; Email: maurizio.benaglia@unimi.it

Alessandra Lattanzi - Dipartimento di Chimica e Biologia "A. Zambelli", Università di Salerno, 84084 Fisciano, Italy; ○ orcid.org/0000-0003-1132-8610; Email: lattanzi@ unisa.it

\section{Authors}

Francesca Franco - Dipartimento di Chimica e Biologia "A. Zambelli", Università di Salerno, 84084 Fisciano, Italy

Sara Meninno - Dipartimento di Chimica e Biologia "A. Zambelli", Università di Salerno, 84084 Fisciano, Italy Alessandra Puglisi - Dipartimento di Chimica, Università degli Studi di Milano, 20133 Milano, Italy; ㅈorcid.org/ 0000-0002-8581-8009

Complete contact information is available at: 
https://pubs.acs.org/10.1021/acs.joc.1c01270

\section{Author Contributions}

The manuscript was written through contributions of all authors.

\section{Notes}

The authors declare no competing financial interest.

\section{ACKNOWLEDGMENTS}

M.B. and A.P. thank ITN-EID project Marie Sklodowska-Curie Actions Innovative Training Network - TECHNOTRAIN H2020-MSCA-ITN-2018 Grant Agreement 812944 (www. technotrain-ITN.eu). A.P. thanks the project PRIN 2017 "SURSUMCAT". F.F. thanks MUR for a PON RI 2014-2020 PhD fellowship. S.M. thanks MUR and the European Union for AIM-international attraction and mobility call for researchers funded by PON RI 2014-2020. MUR and the University of Salerno are acknowledged for financial support (ORSA187525).

\section{DEDICATION}

Dedicated to Prof. Placido Neri (Università di Salerno) on the occasion of his 60th birthday.

\section{REFERENCES}

(1) (a) May, S. A. Flow Chemistry, Continuous Processing, and Continuous Manufacturing: A Pharmaceutical Perspective. J. Flow Chem. 2017, 7, 137-145. (b) Porta, R.; Benaglia, M.; Puglisi, A. Flow Chemistry: Recent Developments in the Synthesis of Pharmaceutical Products. Org. Process Res. Dev. 2016, 20, 2-25.

(2) Hayashi, Y. Pot Economy and One-Pot Synthesis. Chem. Sci. 2016, 7, 866-880.

(3) (a) Kirsch, P., Ed. Modern Fluoroorganic Chemistry: Synthesis, Reactivity, Applications, 2nd ed.; Wiley-VCH: Weinheim, Germany, 2013. (b) Purser, S.; Moore, P. R.; Swallow, S.; Gouverneur, V. Fluorine in Medicinal Chemistry. Chem. Soc. Rev. 2008, 37, 320-330. (c) Wang, J.; Sánchez-Roselló, M.; Aceña, J. L.; del Pozo, C.; Sorochinsky, A. E.; Fustero, S.; Soloshonok, V. A.; Liu, H. Fluorine in Pharmaceutical Industry: Fluorine-Containing Drugs Introduced to the Market in the Last Decade (2001-2011). Chem. Rev. 2014, 114, 2432-2506.

(4) For selected examples, see: (a) Gillis, E. P.; Eastman, K. J.; Hill, M. D.; Donnelly, D. J.; Meanwell, N. A. Applications of Fluorine in Medicinal Chemistry. J. Med. Chem. 2015, 58, 8315-8359. (b) Meanwell, N. A. Fluorine and Fluorinated Motifs in the Design and Application of Bioisosteres for Drug Design. J. Med. Chem. 2018, 61, $5822-5880$

(5) For reviews, see: (a) Yang, X.; Wu, T.; Phipps, R. J.; Toste, F. D. Advances in Catalytic Enantioselective Fluorination, Mono-, Di-, and Trifluoromethylation, and Trifluoromethylthiolation Reactions. Chem. Rev. 2015, 115, 826-870. (b) Chachignon, H.; Cahard, D. Late Stage Trifluoromethylthiolation Strategies for Organic Compounds. Chin. J. Chem. 2016, 34, 445-454. (c) Barata-Vallejo, S.; Bonesi, S.; Postigo, A. Org. Biomol. Chem. 2016, 14, 7150-7182. (d) Zhu, Y.; Han, J.; Wang, J.; Shibata, N.; Sodeoka, M.; Soloshonok, V. A.; Coelho, J. A. S.; Toste, F. D. Modern Approaches for Asymmetric Construction of Carbon Fluorine Quaternary Stereogenic Centers: Synthetic Challenges and Pharmaceutical Needs. Chem. Rev. 2018, 118, 3887-3964. (e) Szabó, K. J., Selander, N., Ed. Organofluorine Chemistry: Synthesis, Modeling, and Applications, 1st ed.; Wiley-VCH: Weinheim, Germany, 2021.

(6) Franco, F.; Meninno, S.; Benaglia, M.; Lattanzi, A. Formal $\alpha$ Trifluoromethylthiolation of Carboxylic Acid Derivatives via $N$-Acyl Pyrazoles. Chem. Commun. 2020, 56, 3073-3076.

(7) For reviews, see: (a) Desimoni, G.; Faita, G.; Quadrelli, P. Enantioselective Catalytic Reactions with $\mathrm{N}$-Acyliden Penta-atomic
Aza-heterocycles. Heterocycles as Masked Bricks To Build Chiral Scaffolds. Chem. Rev. 2015, 115, 9922-9980. (b) Monge, D.; Jiang, H.; Alvarez-Casao, Y. Masked Unsaturated Esters/Amides in Asymmetric Organocatalysis. Chem. - Eur. J. 2015, 21, 4494-4504. (c) Meninno, S.; Franco, F.; Benaglia, M.; Lattanzi, A. Pyrazoleamides in Catalytic Asymmetric Reactions: Recent Advances. Adv. Synth. Catal. 2021, 363, 3380-3410.

(8) For a few selected reviews on flow chemistry in organic synthesis, see: (a) Plutschack, M. B.; Pieber, B.; Gilmore, K.; Seeberger, P. H. The Hitchhiker's Guide to Flow Chemistry. Chem. Rev. 2017, 117, 11796-11893. (b) Gutmann, B.; Cantillo, D.; Kappe, C. O. Continuous-Flow Technology-A Tool for the Safe Manufacturing of Active Pharmaceutical Ingredients. Angew. Chem., Int. Ed. 2015, 54, 6688-6728. (c) Porta, R.; Benaglia, M.; Puglisi, A. Flow Chemistry: Recent Developments in the Synthesis of Pharmaceutical Products. Org. Process Res. Dev. 2016, 20, 2-25. (d) Yu, T.; Ding, Z.; Nie, W.; Jiao, J.; Zhang, H.; Zhang, Q.; Xue, C.; Duan, X.; Yamada, Y. M. A.; Li, P. Recent Advances in Continuous Flow Enantioselective Catalysis. Chem. - Eur. J. 2020, 26, 5729-5747. (e) Yoo, W.-J.; Ishitani, H.; Laroche, B.; Kobayashi, S. Reworking Organic Synthesis for the Modern Age: Synthetic Strategies on Continuous-Flow Addition and Condensation Reactions with Heterogeneous Catalysts. J. Org. Chem. 2020, 85, 5132-5145. (f) Pastre, J. C.; Browne, D. L.; Ley, S. V. Flow Chemistry Syntheses of Natural Products. Chem. Soc. Rev. 2013, 42, 8849-8869. (g) For recent achievements in automated synthesis, see: Chatterjee, S.; Guidi, M.; Seeberger, P. H.; Gilmore, K. Automated Radial Synthesis of Organic Molecules. Nature 2020, 579, 379-384. (h) Adamo, A.; Beingessner, R. L.; Behnam, M.; Chen, J.; Jamison, T. F.; Jensen, K. F.; Monbaliu, J.-C. M.; Myerson, A. S.; Revalor, E. M.; Snead, D. R.; Stelzer, T.; Weeranoppanant, N.; Wong, S. W.; Zhang, P. On-Demand Continuous-Flow Production of Pharmaceuticals in a Compact, Reconfigurable System. Science 2016, 352, 61-67. (i) Bédard, A.-C.; Adamo, A.; Aroh, K. C.; Russell, M. G.; Bedermann, A. A.; Torosian, J.; Yue, B.; Jensen, K. F.; Jamison, T. F. Reconfigurable System for Automated Optimization of Diverse Chemical Reactions. Science 2018, 361, 1220-1225.

(9) For a few selected works on the telescopic process, see: (a) Britton, J.; Raston, C. L. Multi-Step Continuous-Flow Synthesis. Chem. Soc. Rev. 2017, 46, 1250-1271. (b) Vasudevan, N.; Sharma, M. K.; Reddy, D. S.; Kulkarni, A. A. A Multi-Step Continuous Flow Synthesis of the Cystic Fibrosis Medicine Ivacaftor. React. Chem. Eng. 2018, 3, 520-526. (c) Gilmore, K.; Kopetzki, D.; Lee, J. W.; Horváth, Z.; McQuade, D. T.; Seidel-Morgenstern, A.; Seeberger, P. H. Continuous Synthesis of Artemisinin-Derived Medicines. Chem. Commun. 2014, 50, 12652-12655. (d) Murray, P. R. D.; Browne, D. L.; Pastre, J. C.; Butters, C.; Guthrie, D.; Ley, S. V. Continuous Flow-Processing of Organometallic Reagents using an Advanced Peristaltic Pumping System and the Telescoped Flow Synthesis of $(E /$ Z)-Tamoxifen. Org. Process Res. Dev. 2013, 17, 1192-1208. (e) Jiao, J.; Nie, W.; Yu, T.; Yang, F.; Zhang, Q.; Aihemaiti, F.; Yang, T.; Liu, X.; Wang, J.; Li, P. Multi-Step Continuous-Flow Organic Synthesis: Opportunities and Challenges. Chem. - Eur. J. 2021, 27, 4817-4838. (f) Ötvös, S. B.; Llanes, P.; Pericas, M. A.; Kappe, C. O. Telescoped Continuous Flow Synthesis of Optically Active $\gamma$-Nitrobutyric Acids as Key Intermediates of Baclofen, Phenibut, and Fluorophenibut. Org. Lett. 2020, 22, 8122-8126.

(10) See ref 6 and: Abubakar, S. S.; Benaglia, M.; Rossi, S.; Annunziata, R. Organocatalytic $\alpha$-trifluoromethylthiolation of Silylenol Ethers: Batch vs Continuous Flow Reactions. Catal. Today 2018, 308, 94-101.

(11) The ${ }^{19} \mathrm{~F}$ NMR experiments were recorded with $d_{1}=5 \mathrm{~s}$ to obtain a quantitative analysis. The product conversion was evaluated by the integral ratio between the signal of $\mathrm{SCF}_{3}$ group of the product $(\sim-40 \mathrm{ppm})$ and the signal of the $\mathrm{CF}_{3}$ group of the internal standard $(-63 \mathrm{ppm})$ 